\title{
An error frequently made in the evaluation of advective transport in two-dimensional Lagrangian models of advection-diffusion in coral reef waters
}

\author{
S. Spagnol ${ }^{1, *}$, E. Wolanski ${ }^{1}$, E. Deleersnijder ${ }^{2}$, R. Brinkman ${ }^{1}$, F. McAllister ${ }^{1}$, \\ B. Cushman-Roisin ${ }^{3}$, E. Hanert ${ }^{2}$ \\ ${ }^{1}$ Australian Institute of Marine Science, PMB No. 3, Townsville MC, Queensland 4810, Australia \\ ${ }^{2}$ Institut d'astronomie et de géophysique Georges Lemaître, Université catholique de Louvain, 2 Chemin du cylcotron, \\ 1348 Louvain-la-Neuve, Belgium \\ ${ }^{3}$ Thayer School of Engineering, Dartmouth College, Hanover, New Hampshire 03755-8000, USA
}

\begin{abstract}
The flushing time of reef lagoons estimated over recent years by 2-dimensional Lagrangian algorithms may have been significantly overestimated. This is due to a numerical artefact, leading to spurious accumulation of particles in regions where the water depth or the diffusivity is smallest. The nature of this numerical problem has remained largely unknown in the coral reef modelling community, although it was described, along with an efficient remedy, in several studies which are about a decade old. The numerical problem under consideration and its consequences on the modelled transport of coral eggs at Bowden Reef, Great Barrier Reef, are briefly assessed in the present article.
\end{abstract}

KEY WORDS: Particle tracking - Lagrangian algorithms · Advection-diffusion equation

Resale or republication not permitted without written consent of the publisher

In a 2-dimensional approach in which the vertical dependency of variables is not taken into account, the concentration $C$ of a passive tracer is governed by the Eulerian equation:

$$
\frac{\partial\left(h_{C}\right)}{\partial t}=-\nabla \cdot\left(u_{C}-h k \nabla C\right)
$$

where $t, h(>0)$ and $k(>0)$ denote time, the water depth and the horizontal diffusivity, respectively; $\boldsymbol{u}$ is the depth-averaged horizontal water velocity; $\nabla \bullet$ and $\nabla$ represent the 2-dimensional divergence and gradient operators. Accurate numerical solutions of Eq. (1) are not easy to obtain, for want of appropriate Eulerian

*E-mail: s.spagnol@aims.gov.au discretisations of the advective operator $-\nabla \bullet(u h c)$. This is why many modellers opted instead for a Lagrangian approach. For instance, numerous coral reef studies have had recourse to a Lagrangian numerical method to predict the fate of water-born propagules near coral reefs, principally sewage, coral eggs and larvae, plankton, fish and crown-of-thorn starfish (Sammarco \& Andrews 1988, 1989, Wolanski et al. 1989, 1997, Black et al. 1990, 1991, Dight et al. 1990, Black \& Moran 1991, Oliver et al. 1992, Black 1993, Roberts 1999, Kim et al. 2000).

All the above-mentioned coral reef studies rely on a similar Lagrangian algorithm: at time $(t), t_{n}=n \Delta t$ $(n=1,2,3, \ldots)$, where $\Delta t$ is a suitable time increment, the position $(\boldsymbol{x}), \boldsymbol{x}_{n}=\left(x_{n}, y_{n}\right)$ of a water-born propagule is updated by means of the Lagrangian algorithm:

$$
\boldsymbol{x}_{n+1}=\boldsymbol{x}_{n}+\mathbf{v} \Delta t+\frac{\boldsymbol{R}_{n}}{\sqrt{r}} \sqrt{2 k \Delta t}
$$

where the velocity $\boldsymbol{V}$ is set equal to $\boldsymbol{u}_{;} \boldsymbol{R}_{\mathrm{n}}$ is a horizontal vector of which the components are zero-mean random numbers with variance equal to $r$. It is believed that the propagule concentration, which may be inferred from the positions of the propagules as calculated by the Lagrangian algorithm (Eq. 2), tends to be equivalent, as the number of propagules increases, to the solution of the Eulerian advection-diffusion Eq. (1). However, if $h$ or $k$ vary in space, this is incorrect. Implementation of Eq. (2) tends to accumulate particles in regions where $h$ or $k$ is small. This numerical artefact has already been described by authors including Hunter (1987), Dimou \& Adams (1993), Hunter et al. (1993), Scott (1997), and Visser (1997). 
Corrections to the algorithm (Eq. 2), so that the corresponding concentration tends towards that derived from the Eulerian Eq. (1), were suggested by Hunter (1987), Heemink (1990), Dimou \& Adams (1993), and Hunter et al. (1993), but have largely been ignored in the coral reef modelling community. Therefore, we feel it necessary to present once again the modified Lagrangian algorithm that should be used, and briefly illustrate the significant discrepancies between the results of the algorithm given by Eq. (2) and those of the modified algorithm.

Modified Lagrangian algorithm. Eq. (1) may be rewritten as:

$$
\frac{\partial(h c)}{\partial t}=-\nabla \cdot\left[\left(\boldsymbol{u}+k h^{-1} \nabla h\right) h c-k \nabla(h c)\right]
$$

If $k$ is the horizontal diffusitivity constant, Eq. (3) may be regarded as an advection diffusion equation for which the quantity to be transported is $h c$, and the advection velocity is $\boldsymbol{u}+k h^{-1} \nabla h$ (Hunter 1987). The equivalent particle-tracking algorithm is then readily seen as Eq. (2), in which the marching velocity $\mathbf{v}$ must be taken as:

$$
\boldsymbol{v}=\boldsymbol{u}+\frac{k}{h} \nabla h
$$

If the diffusivity varies in space, the generic algorithm (Eq. 2) is still valid, provided that:

$$
\boldsymbol{v}=\boldsymbol{u}+\frac{k}{h} \nabla h+\nabla k
$$

which is in accordance with Hunter et al. (1993). The physical interpretation is as follows: the rate of spreading of a propagule cloud is unaffected locally by the space variability of the water depth or the diffusivity, but the centre of mass of the cloud moves with velocity $\boldsymbol{V}$, which is the sum of the depth-averaged water velocity and a correction velocity, $\boldsymbol{u}^{\prime}=\boldsymbol{V}-\boldsymbol{u}$. The correction velocity tends to transport particles towards regions of increasing depth and diffusivity. Therefore, overlooking this necessary correction biases movements of particles toward the parts of the domain where the depth and diffusivity are lowest.

Application to coral reefs. The impact of the correction velocity is illustrated in a model of Bowden Reef $\left(147^{\circ} 56^{\prime} \mathrm{E}, 1^{\circ} 02^{\prime} \mathrm{S}\right.$; see Fig. 1a) in the Great Barrier Reef of Australia. Bowden Reef is about $6 \mathrm{~km}$ long and $3 \mathrm{~km}$ wide. It has a semi-enclosed lagoon typically 10 to $20 \mathrm{~m}$ deep and an extensive reef flat, and surrounding waters are 40 to $50 \mathrm{~m}$ deep. The bathymetry has been surveyed at a horizontal resolution of $30 \mathrm{~m}$. The model domain is described by Oliver et al. (1992): it is about $25 \times 20 \mathrm{~km}$, with Bowden Reef located in the centre of the model domain. The mesh size is $100 \mathrm{~m}$, so that small-scale topographic features can be resolved. The open boundary conditions are observed tides, wind and currents in the far field (Oliver et al. 1992). The hydrodynamic and Lagrangian particle transport models are based on Wolanski \& King (1990) and Oliver et al. (1992).

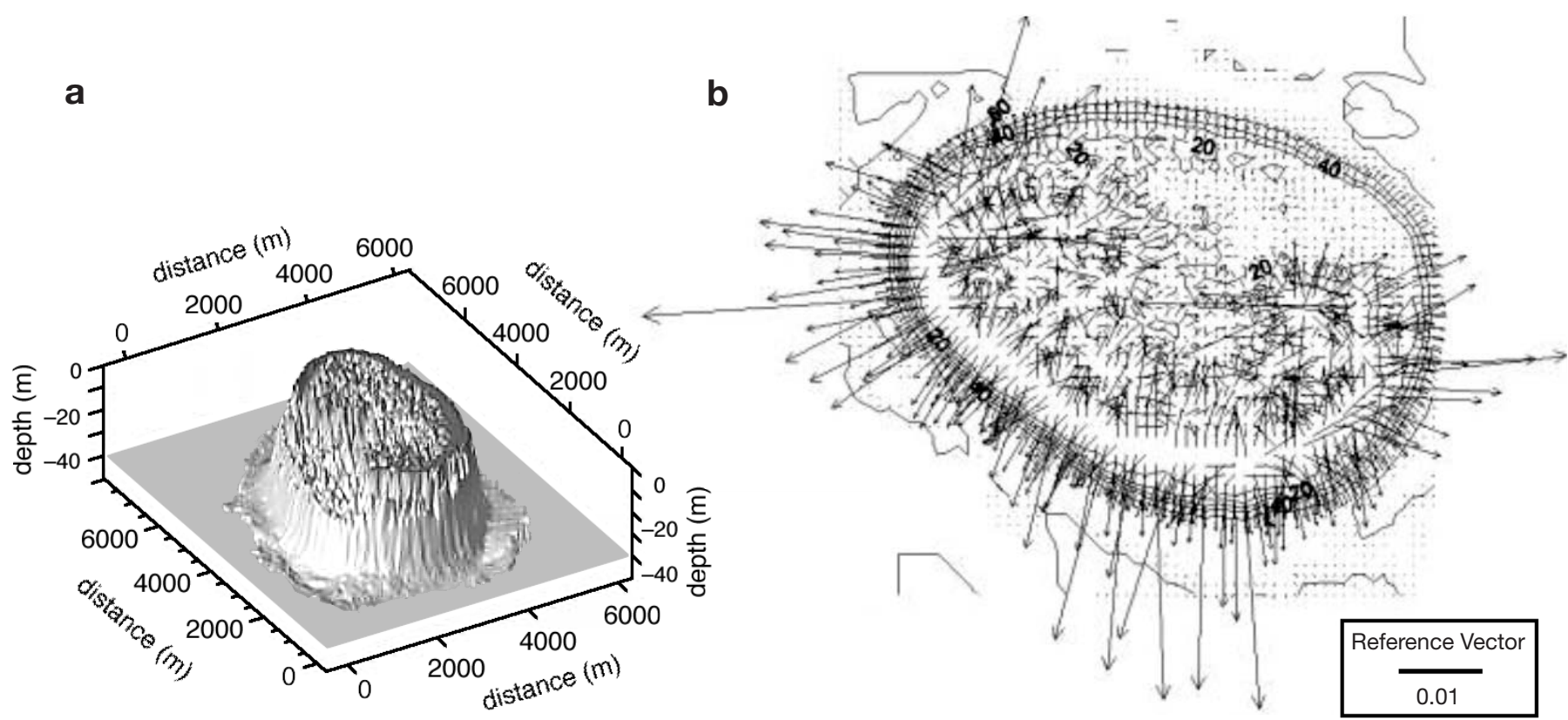

Fig. 1. (a) Three-dimensional rendering of Bowden Reef bathymetry, Great Barrier Reef, and (b) spatial distribution of the correction velocity $\mathbf{u}^{\prime}=k h^{-1}(\partial h / \partial x, \partial h / \partial y)$ for $k=0.5 \mathrm{~m}^{2} \mathrm{~s}^{-1}$. The reference vector displayed in the lower panel corresponds to $0.01 \mathrm{~m} \mathrm{~s}^{-1}$ 
The dispersion of coral eggs following the mass coral spawning of 1987 is simulated numerically. According to Oliver et al. (1992), the coral eggs are instantaneously released over the coral reef. After mass spawning, no additional propagules are added in the model. The position of the coral eggs is calculated by the Lagrangian algorithm (Eq. 2).

A model sensitivity study is carried out. The diffusivity $k$ does not vary in space, so that the velocity $\boldsymbol{v}$ is given in Eq. (4). In other words, the correction velocity to be added to the depthmean water velocity is due the bathymetry variations only, and is given by:

$$
\boldsymbol{u}^{\prime}=\frac{k}{h} \nabla h=\frac{k}{h}\left(\frac{\partial h}{\partial x}, \frac{\partial h}{\partial y}\right)
$$

In half of the model runs, the correction above is taken into account, whereas it is disregarded in the other numerical experiments. Three values of the diffusion are considered, i.e. $k=0.5,1.0$ and $2.0 \mathrm{~m}^{2} \mathrm{~s}^{-1}$.

The correction velocity $\mathbf{u}^{\prime}$ (Fig. 1b) varies strongly spatially, is directed away from shallow waters and has a maximum value of about $0.03 \mathrm{~m} \mathrm{~s}^{-1}$.

This velocity is small compared to instantaneous tidal currents, which peak at about $0.3 \mathrm{~m} \mathrm{~s}^{-1}$. It is however not negligible compared to the mean currents which for the few days following the 1987 mass spawning varied between typically $0.05 \mathrm{~m} \mathrm{~s}^{-1}$ in open waters and $0.02 \mathrm{~m}$ $\mathrm{s}^{-1}$ in the inner region of the lagoon (Oliver et al. 1992).

The importance of the numerical correction is assessed by means of ratio $R$ (Fig. 2):

$$
R=\frac{n_{\text {with correction }}}{n_{\text {without correction }}}
$$

where $n_{\text {with correction }}$ is the predicted number of coral eggs in the reef area when the correction velocity (Eq. 6) is applied, and $n_{\text {without correction }}$ is the same number when no correction velocity is applied, i.e. $\boldsymbol{v}=\boldsymbol{u}$. The ratio $R$ generally diminishes as time progresses. Moreover, at a given time, the larger the diffusivity $k$, the smaller the ratio $R$, which is not surprising since the correction velocity $\boldsymbol{u}^{\prime}$ is an increasing function of $k$, and is generally directed from the reef area toward the sea surrounding the reef. Finally, the most striking aspect of the evolution of $R$ is that this ratio becomes rather small in just a few tens of hours, implying that predictions made without the correction velocity are severely compromised in a relatively short time.
Acknowledgements. Eric Deleersnijder and Emmanuel Hanert are a Research associate and Research fellow, respectively, with the Belgian National Fund for Scientific Research (FNRS).

\section{LITERATURE CITED}

Black KP (1993) The relative importance of local retention and inter-reef dispersal of neutrally buoyant material on coral reefs. Coral Reefs 12:43-53

Black KP, Moran PJ (1991) Influence of hydrodynamics on the passive dispersal and initial recruitment of larvae of Acanthaster planci (Echinodermata: Ateroidea) on the Great Barrier Reef. Mar Ecol Prog Ser 69:55-65

Black KP, Gay SG, Andrews JC (1990) Residence times of neutrally buoyant matter such as larvae, sewage or nutrients on coral reefs. Coral Reefs 9:105-114

Black KP, Moran PJ, Hammond LS (1991) Numerical models show coral reefs can be self-seeding. Mar Ecol Prog Ser 74:1-11

Dight IJ, James MK, Bode L (1990) Modelling the larval dispersal of Acanthaster planci. II. Patterns of reef connectivity. Coral Reefs 39:125-134

Dimou KN, Adams EE (1993) A random-walk, particle tracking model for well-mixed estuaries and coastal waters. Estuar Coast Shelf Sci 37:99-110

Heemink AW (1990) Stochastic modelling of dispersion in shallow water. Stochastic Hydrology and Hydraulics 4: 161-174 
Hunter JR (1987) The applications of Lagrangian particletracking techniques to modelling of dispersion in the sea. In: Noye J (ed) Numerical modelling: applications to marine systems. Elsevier Science Publishers, Amsterdam, p 295

Hunter JR, Craig PD, Phillips HE (1993) On the use of random walk models with spatially variable diffusivity. J Comput Phys 106:366-367

Kim YD, Kang SW, Seo IW, Oh BC (2000) Far-field transport of effluent plumes discharged from Masan Sea outfalls. Ocean Res 22(2):69-80

Oliver J, King B, Willis B, Babcock R, Wolanski E (1992) Dispersal of coral larvae from a coral reef: comparison between model predictions and observed concentrations. Cont Shelf Res 12:873-891

Roberts PJW (1999) Modelling Mamala Bay outfall plumes. J Hydraul Eng 125(6):574-583

Sammarco PW, Andrews JC (1988) Localized dispersal and

Editorial responsibility: Charles Birkeland (Contributing Editor), Honolulu, Hawaii, USA recruitment in Great Barrier Reef corals: the Helix experiment. Science 239:1422-1424

Sammarco PW, Andrews JC (1989) The Helix experiment: differential localized dispersal and recruitment patterns in Great Barrier Reef corals. Limnol Oceanogr 34:896-912

Scott CF (1997) Particle tracking simulation of pollutant discharges. J Environ Eng 123(9):919-927

Visser AW (1997) Using random walk models to simulate the vertical distribution of particles in a turbulent water column. Mar Ecol Prog Ser 158:275-281

Wolanski E, King B (1990) Flushing of Bowden Reef lagoon, Great Barrier Reef. Estuar Coast Shelf Sci 31:789-804

Wolanski E, Burrage D, King B (1989) Trapping and dispersal of coral eggs around Bowden Reef, Great Barrier Reef, following mass spawning. Cont Shelf Res 9:479-496

Wolanski E, Doherty P, Carleton J (1997) Directional swimming of fish larvae determines connectivity of fish populations on the Great Barrier Reef. Naturwissenschaften 84:262-282

Submitted: August 30, 2001; Accepted: November 24, 2001 Proofs received from author(s): May 15, 2002 